\title{
Epidemiology of medical error
}

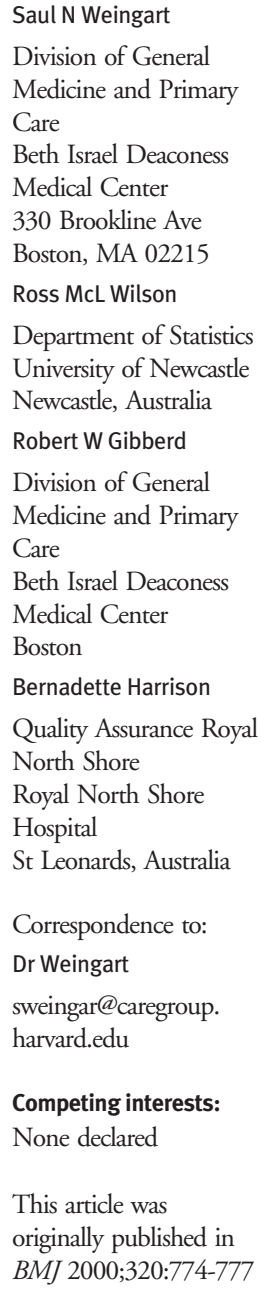

Newspaper and television stories of catastrophic injuries occurring at the hands of physicians spotlight the problem of medical error but provide little insight into its nature or magnitude. ${ }^{1}$ Physicians, patients, and policymakers may underestimate the magnitude of risk and the extent of harm. We review the epidemiology of medical error, concentrating primarily on the prevalence and consequences of error, which types are most common, which physicians make errors, and the risk factors that increase the likelihood of injury from error.

\section{PREVALENCE AND CONSEQUENCES IN HOSPITALS \\ Benchmark studies}

The Harvard study of medical practice is the benchmark for estimating the extent of medical injuries occurring in hospitals. Brennan et al reviewed the medical records of 30,121 patients admitted to 51 acute care hospitals in New York State in 1984. ${ }^{2}$ They reported that adverse events-injuries caused by medical management that prolonged admission or produced disability at the time of discharge—occurred in $3.7 \%$ of admissions.

A subsequent analysis of the same data found that $69 \%$ of injuries were caused by errors. ${ }^{3}$ In a study of the quality of Australian health care, a population-based study modeled on the Harvard study, investigators reviewed the medical records of 14,179 patients admitted to 28 hospitals in New South Wales and South Australia in 1995. ${ }^{4}$ An adverse event occurred in $16.6 \%$ of admissions, resulting in permanent disability in $13.7 \%$ of patients and death in $4.9 \%$; $51 \%$ of adverse events were considered to have been preventable. The number of preventable adverse events is important because both preventable and potentially adverse events (or "near misses") imply medical error. In contrast, nonpreventable adverse events suggest that anticipated and unavoidable complications were present. In the Australian study, the higher rate of adverse events was attributed in part to methodologic differences between the 2 studies, but a real difference in the rate of injuries to patients in the 2 populations could not be excluded.

No study rivals the scope of the Harvard and the Australian studies except for a recent replication of the Harvard study in Colorado and Utah. ${ }^{5}$ Even so, the results probably represent an estimate of the lower boundary of the prevalence of medical injury and error. The Harvard investigators defined adverse events stringently, using disability and injury as prerequisites. This underestimates the error rate because many errors do not produce injury; they are caught in time, the patient is resilient, or luck is good.

\section{Beyond medical record review}

Aggressive case finding may identify injuries and errors that are not documented in patients' medical records. ${ }^{6}$ Using a computerized model to detect adverse drug events among patients at a hospital in Salt Lake City, Utah, Classen et al found that adverse

\section{Summary points}

- The Harvard and Australian studies of medical error are the only studies that provide population data on the rates of injuries of patients in hospitals, and they identified a substantial amount of medical error

- In the United States, medical error results in 44,000 to 98,000 unnecessary deaths each year and 1 million excess injuries

- Errors often occur when clinicians are inexperienced and new procedures are introduced

- Extremes of age, complex care, and a prolonged hospital stay are associated with more errors

drug events occurred in $1.7 \%$ of admissions. ${ }^{7}$ In comparison, using both medical record review and prompted self-reports from physicians, Bates et al found that adverse drug events occurred among $6.5 \%$ of patients and that potential adverse drug events occurred among $5.5 \%$ of patients admitted to 2 teaching hospitals in Boston. ${ }^{8}$ Of the adverse drug events, $28 \%$ were due to errors, making the rate of serious medication errors - that is, preventable plus potential adverse drug events-7.3\%. Both of these studies reported rates that are much higher than the $0.7 \%$ rate of adverse drug events identified in the Harvard study's review of medical records.

Observational studies, although costly, have identified even higher rates of error and injury occurring during medical care. For example, observers on the general surgical units of a Chicago teaching hospital who recorded all "situations in which an inappropriate decision was made when, at the time, an appropriate alternative could have been chosen" found that $45.8 \%$ of patients had an adverse event. ${ }^{9}$ Eighteen percent of these patients had a serious adverse event - that is, one that produced at least temporary disability. Similarly, Donchin et al placed an observer at patients' bedsides to observe physicians in the medical-surgical intensive care unit of a university hospital in Israel. ${ }^{10}$ Clinicians made 554 errors during 4 months, or 1.7 errors per patient per day. Patients injured as a result of a medical error stay in a hospital longer and have higher hospital costs. At the hospital in Utah, adverse drug events caused complications in $2.4 \%$ of admissions, cost an average of $\$ 2,262$ per patient, and lengthened the stay by 1.9 days compared with matched controls. ${ }^{11}$

In the Harvard study of adverse drug events, the incremental cost associated with an event was $\$ 2,595$, and the length of stay was increased by 2.2 days. Among preventable adverse drug events, however, the excess cost was $\$ 4,685$, and the length of stay was increased by 4.6 days. ${ }^{12}$ The cost of adverse drug events for a 700-bed teaching hospital was estimated to be $\$ 5.6$ million a year. Thus, medical error is ubiquitous, and the costs are substantial. In Australia, medical error results in as many as 18,000 unnecessary deaths, and more than 50,000 patients become disabled each year. In the United States, medical error results in at least 44,000 (and perhaps as many as 98,000) unnecessary deaths each year and 1 million excess injuries. ${ }^{13}$ 


\section{PREVALENCE AND CONSEQUENCES AMONG OUTPATIENTS}

Comparatively little is known about the prevalence of medical error outside of hospitals. In both the Harvard and the Australian studies, about $9 \%$ of adverse events occurred in a physician's office, up to $3 \%$ at home, and as many as $2 \%$ in nursing homes. In the Australian study, about a quarter of the adverse events occurring among outpatients caused permanent disability or death, and investigators judged it likely that more than two thirds could have been prevented. In other studies, iatrogenic injury accounted for $5 \%$ to $36 \%$ of admissions to medical services $^{14^{-16}}$ and between $11 \%$ and $13 \%$ of adult admissions to intensive care units at several university hospitals. ${ }^{17-19}$ Because these studies included only errors that were serious enough to require admission, these figures underestimate the extent of error associated with outpatient care. Data on risk management also underestimate medical error occurring among outpatients because there is little association between malpractice claims and medical error. ${ }^{20}$

Asking physicians and patients about errors elicits more useful information. Burnum reported that in a series of 1,000 consecutive patients seen in his 3-person internal medicine practice, 42 adverse drug reactions occurred, of which 10 were preventable. ${ }^{21}$ More recently, Bhasale et al collected anonymous incident reports from Australian general practitioners of "an unintended event ... that could have harmed or did harm a patient."22 Of 805 incidents involving drug treatment, diagnosis, and equipment, $27 \%$ had the potential to cause severe harm, and $76 \%$ were judged to have been preventable. In the most rigorous outpatient study, Gandhi et al evaluated complications associated with medications among patients at 11 primary care sites in Boston. ${ }^{23}$ Of 2,258 patients who had had drugs prescribed, 18\% reported having had a drug-related complication, such as gastrointestinal symptoms, sleep disturbance, or fatigue, in the previous year.

To calculate the cost of drug-related morbidity and mortality among outpatients in the United States, Johnson and Bootman asked pharmacists to estimate the probability of adverse outcomes occurring as a result of drug treatment. ${ }^{24}$ The costs associated with adverse outcomes were taken from statistical and research reports. The authors calculated that drug-related problems accounted for 116 million extra visits to a physician per year, 76 million additional prescriptions, 17 million emergency department visits, 8 million admissions to hospital, 3 million admissions to long-term care facilities, and 199,000 additional deaths. The total cost was estimated to be $\$ 76.6$ billion, rivaling the aggregate cost of caring for patients who have diabetes.

\section{TYPES OF MEDICAL ERROR}

In both the Harvard and the Australian studies, about half of the adverse events occurring among inpatients resulted from surgery. Complications from drug treatment, therapeutic mishaps, and diagnostic errors were the most common nonoperative events. In the Australian study, cognitive errors, such as making an incorrect diagnosis or choosing the wrong medication, were more likely to have been preventable and more likely to result in permanent disability than technical errors. ${ }^{25}$ Adverse drug events have been investigated extensively because they are prevalent and preventable.
In Bates et al's study of adverse drug events at 2 teaching hospitals in Boston, $1 \%$ of the events were fatal, $12 \%$ were life-threatening, $30 \%$ were serious, and $57 \%$ were significant. ${ }^{8}$ Of the adverse events classified as life-threatening or serious, $42 \%$ were preventable. Errors resulting in preventable adverse events occurred most often during ordering (56\%) and administering (24\%). Altogether, 245 of the near misses were the result of ordering errors, and $40 \%$ were the result of errors in administering drugs. Adverse events were associated with the use of analgesics, antibiotics, sedatives, chemotherapeutic agents, cardiovascular drugs, and anticoagulants. ${ }^{8}$

Missed and delayed diagnoses may be difficult to detect retrospectively by medical record review unless patients continue to use the same sources of care. In the Australian study, errors of omission outnumbered errors of commission by 2 to 1 . An error of omission is a failure of action, such as a missed diagnosis, a delayed evaluation, or a failure to prescribe needed drug treatment. An error of commission is an incorrect action, such as administering the wrong drug to the wrong patient at the wrong time. Necropsy studies can also uncover missed diagnoses and misdiagnoses. A study of 61 patients who died in a Spanish emergency department identified unexpected major findings, such as malignant tumors or hemorrhagic pancreatitis, in 27 patients (44\%) and important discrepancies between the necropsy report and the clinical diagnosis in 16 patients $(26 \%){ }^{26}$

In a retrospective study of 524 deaths occurring in 19901991 at a Spanish tertiary care hospital, more than half of the risk of death was accounted for by adverse events that resulted from clinical care. ${ }^{27}$ The number of misdiagnoses and major unexpected findings at necropsy has remained essentially unchanged for more than 40 years, prompting health care leaders to cite the falling rate of necropsy as an important impediment to ensuring the safety of patients. ${ }^{28}$

\section{PHYSICIANS WHO MAKE ERRORS}

Despite rare examples of malevolent physicians, there is little evidence that much medical error is due to "bad apples." 29 Although anesthesiologists pioneered modern research into the safety of patients, no specialty is immune to error. ${ }^{30}$ Procedural mishaps are common in surgical specialties, perhaps because they are hard to disguise. Mistakes may be more common when a physician is inexperienced and when new techniques are introduced. ${ }^{31}$ Misread radiographs and pathology specimens, ${ }^{32}$ laboratory errors, ${ }^{33}$ and mistakes made in administering radiation therapy also threaten the safety of patients. ${ }^{34}$ Trainees often err. Wu et al surveyed medical house officers in 3 training programs in internal medicine about their most serious mistake. ${ }^{35}$ Altogether, $45 \%$ reported making at least 1 error, $31 \%$ of which resulted in a patient's death. Lesar et al found that more prescribing errors occurred among first-year postgraduate residents than among other physicians. ${ }^{36}$ Wilson et al found that more errors occurred in a pediatric intensive care unit when new physicians joined the rotation. ${ }^{37}$

\section{RISK FACTORS FOR INJURY}

A potentially attractive strategy for preventing injury from medical error is to identify which patients are at an increased risk of 
harm. Patients older than 64 years, for example, have a greater risk of serious injury from adverse events than younger patients. $^{2,4,7,8}$ This may reflect their greater burden of comorbid illness and frailty. Certain interventions signal that there is a high risk, such as cardiothoracic surgery, vascular surgery, and neurosurgery. The severity of a patient's underlying illnesses and the inherent hazards of certain procedures may increase the likelihood of poor outcomes. Wilson et al found that a greater risk of death and a greater number of preventable adverse events were associated with patients with complex cases, illnesses requiring urgent care, and the use of interventions thought to be potentially lifesaving. ${ }^{4}$ Being cared for in an emergency department causes many preventable adverse events. ${ }^{2,4,38}$ Several factors are implicated: the use of part-time physicians not trained in emergency care; fluctuating demand for services, which results in uneven and sometimes abbreviated care; the limited time available to arrive at a definitive diagnosis; and the fact that emergency departments are the point of entry for acutely ill patients.

The characteristics of individual patients may be less important than the duration of care in explaining injury. Andrews et al reported that the likelihood of an adverse event increased by $6 \%$ for each day spent in a hospital. ${ }^{9}$ The intensity of care also affects the risk of injury. Among pediatric patients admitted to a British university hospital, drug errors were 7 times more likely to occur in the intensive care unit than elsewhere. ${ }^{37}$ Similarly, the Harvard investigators looking at adverse drug events found that these events occurred more often among adult patients in medical intensive care units than in surgical intensive care units or general medical and surgical wards. ${ }^{39}$ When the number of doses dispensed in the different units was adjusted for, however, the differences were not significant. In a subsequent analysis of the study, no independent risk factors for preventable adverse events were identified after the length of stay before the event and the use of intensive care were controlled for.

\section{DISCUSSION}

Although researchers regularly publish studies of medical error, adequate epidemiologic information is limited to a few institutions, procedures, and specialties. Because most studies were conducted in academic referral centers, the results may not be generalizable to community-based hospitals and outpatient care facilities.

Comparing studies is difficult because research methods are not standardized. The lack of agreement about methods and the variable rigor of their application contribute to the variations found in error rates. There is a serious need for researchers to use consistent definitions and methods and for collaborative work on measuring error. Systems for monitoring and reporting error could provide the platform from which more detailed studies of subpopulations could develop. However, expecting that individuals will carry out health care flawlessly creates an environment in which clinicians are reluctant to report their errors. Universal underreporting, in turn, undermines the ability to measure error accurately. For these reasons, the precise prevalence and magnitude of medical error is unknown, but it is probably enormous.

We are aware of no study showing that medical care can be provided without error. In fact, the more closely we examine patient care, the more error we find. No setting is free from hazards; no specialty is immune; and patients are at risk no matter what their age, sex, or health status. But the risk is not homogeneous. Patients who are sicker, subjected to multiple interventions, and remain in hospital longer are more likely to suffer serious injury as a result of medical mistakes. Unless we make substantial changes in the organization and delivery of health care, all patients - particularly the most vulnerable - will continue to bear the burden of medical error.

References

1 Cook RI, Woods DD, Miller C. A Tale of Two Stories: Contrasting Views of Patient Safety. Chicago, IL: National Patient Safety Foundation, American Medical Association; 1998.

2 Brennan TA, Leape LL, Laird NM, et al. Incidence of adverse events and negligence in hospitalized patients. $N$ Engl J Med 1991;324:370-376.

3 Leape LL, Lawthers AG, Brennan TA, Johnson WG. Preventing medical injury. QRB Qual Rev Bull 1993;19:144-1449.

4 Wilson RM, Runciman WB, Gibberd RW, Harrison BT, Newby L, Hamilton JD. The Quality in Australian Health Care Study. Med J Aust 1995; 163:458-471.

5 Gawande AA, Thomas EJ, Zinner MJ, Brennan TA. The incidence and nature of surgical adverse events in Colorado and Utah in 1992. Surgery 1999;126:66-75.

6 O'Neil AC, Petersen LA, Cook F, et al. Physician reporting compared with medical-record review to identify adverse medical events. Ann Intern Med 1993;119:370-376.

7 Classen DC, Pestotnik SL, Evans RS, Burke JP. Computerized surveillance of adverse drug events in hospitalized patients. JAMA 1991;266:2847-2851.

8 Bates DW, Cullen DJ, Laird N, et al. Incidence of adverse drug events and potential adverse drug events. JAMA 1995;274:29-34.

9 Andrews LB, Stocking C, Krizek T, et al. An alternative strategy for studying adverse events in medical care. Lancet 1997;349:309-313.

10 Donchin Y, Gopher D, Olin M, et al. A look into the nature and causes of human errors in the intensive care unit. Crit Care Med 1995;23:294-300.

11 Classen DC, Pestotnik SL, Evans RS, Lloyd JF, Burke JP. Adverse drug events in hospitalized patients: excess length of stay, extra costs, and attributable mortality. JAMA 1997;277:301-306.

12 Bates DW, Spell N, Cullen DJ, et al. The costs of adverse drug events in hospitalized patients. JAMA 1997;277:307-311.

13 Kohn LT, Corrigan JM, Donaldson MS, eds. To Err Is Human: Building a Safer Health System. Washington, DC: National Academy Press; 1999.

14 Shimmel EM. The hazards of hospitalization. Ann Intern Med 1964;60:100-101.

15 Steel KS, Gertman PM, Crescenzi C, Anderson J. Iatrogenic illness on a general medical service at a university hospital. $N$ Engl J Med 1981;304:638-642

16 Lakshmanan MC, Hershey CO, Breslau D. Hospital admissions caused by iatrogenic disease. Arch Intern Med 1986;146:1931-1934.

17 Trunet P, Le Gall JR, Lhoste F, et al. The role of iatrogenic disease in admission to intensive care. JAMA 1980;244:2617-2620.

18 Darchy B, Le Miere E, Figueredo B, Bavoux E, Domart Y. Iatrogenic diseases as a reason for admission to the intensive care unit: incidence, causes, and consequences. Arch Intern Med 1999;159:71-78.

19 Stambouly JJ, McLaughlin LL, Mandel FS, Boxer RA. Complications of care in a pediatric intensive care unit: a prospective study. Intensive Care Med 1996;22:1098-1104.

20 Brennan TA, Sox CM, Burstin HR. Relation between negligent adverse events and the outcomes of medical-malpractice litigation. $N$ Engl $J$ Med 1996;335:1963-1967

21 Burnum JF. Preventability of adverse drug reactions [Letter]. Ann Intern Med 1976;85:80-81.

22 Bhasale AL, Miller GC, Reid SE, Britt HC. Analysing potential harm in Australian general practice: an incident-monitoring study. Med J Aust 1998;169:73-76. 
23 Gandhi TK, Bates DW, Burstin HR, et al. Drug complications in outpatients. J Gen Intern Med 2000;15:149-154.

24 Johnson JA, Bootman JL. Drug-related morbidity and mortality and the economic impact of pharmaceutical care. Am J Health Syst Pharm 1997;54:554-558.

25 Wilson RM, Harrison BT, Gibberd RW, Hamilton JD. An analysis of the causes of adverse events from the Quality in Australian Health Care Study. Med J Aust 1999;170:411-415.

26 Balaguer Martinez JV, Gabriel Botella F, Braso Aznar JV, Nunez Sanchez C, Catala Barcelo T, Labios Gomez M. The role of clinical autopsy in monitoring the quality of the clinical diagnosis in an emergency department [in Spanish]. An Med Interna 1998;15:179-182.

27 Garcia-Martin M, Lardelli-Claret P, Bueno-Cavanillas A, Luna-del-Castillo JD, Espigares-Garcia M, Galvez-Vargas R. Proportion of hospital deaths associated with adverse events. J Clin Epidemiol 1997;50:1319-1326.

28 Lundberg GD. Low-tech autopsies in an era of high-tech medicine: continued value for quality assurance and patient safety [Editorial]. JAMA 1998;280:1273-1274.

29 Leape LL. Error in medicine. JAMA 1994;272:1851-1857.

30 Cooper JB, Newbower RS, Kitz RJ. An analysis of major errors and equipment failures in anesthesia management: considerations for prevention and detection. Anesthesiology 1984;60:34-42.
31 Windsor JA, Pong J. Laparoscopic biliary injury: more than a learning curve problem. Aust N Z J Surg 1998;68:186-189.

32 Mitchell H, Medley G, Giles G. Cervical cancers diagnosed after negative results on cervical cytology: perspective in the 1980s. BMJ 1990;300:1622-1626.

33 Plebani M, Carraro P. Mistakes in a stat laboratory: types and frequency. Clin Chem 1997;43:1348-1351.

34 Macklis RM, Meier T, Weinhous MS. Error rates in clinical radiotherapy. J Clin Oncol 1998;16:551-556.

35 Wu AW, Folkman S, McPhee SJ, Lo B. Do house officers learn from their mistakes? JAMA 1991;265:2089-2094.

36 Lesar TS, Briceland LL, Delcoure K, Parmalee CJ, Masta-Gornic V, Pohl H. Medication prescribing errors in a teaching hospital. JAMA 1990;263:2329-2334

37 Wilson DG, McArtney RG, Newcombe RG, et al. Medication errors in paediatric practice: insights from a continuous quality improvement approach. Eur J Pediatr 1998;157:769-774.

38 Leape LL, Brennan TA, Laird N, et al. The nature of adverse events in hospitalized patients. N Engl J Med 1991;324:377-384.

39 Bates DW, Miller EB, Cullen DJ, et al. Patient risk factors for adverse drug events in hospitalized patients. Arch Intern Med 1999;159:2553-2560 